\title{
'They don't want to give people bad news': a qualitative exploration of the potential of prognostic indicators for initiating and supporting difficult conversations at the end-of-life
}

Jane Griffiths ( $\square$ jane.griffiths@manchester.ac.uk)

The University of Manchester

\section{K. Spencer}

The University of Manchester

P. Stone

UCL
A. K. Kalpakidou

UCL

\section{Keeley}

University Hospitals of Derby and Burton NHS Foundation Trust

\section{P. Buckle}

D-A Finlay

C. Todd

The University of Manchester

\section{Research Article}

Keywords: palliative, prognostication, communication, qualitative

Posted Date: June 4th, 2021

DOl: https://doi.org/10.21203/rs.3.rs-569215/v1

License: (9) This work is licensed under a Creative Commons Attribution 4.0 International License. Read Full License 


\section{Abstract}

Background There is increasing evidence that patients with incurable cancer approaching the end-of-life, their carers and clinicians want to know how much time is left to live. Prognostic models can help with planning for the end of life and sorting out affairs, but we know very little about the acceptability of the models to patients, carers and clinicians.

Method Semi-structured interviews were conducted with a purposive sample of 29 patients, 20 carers and 32 clinicians who took part in a large validation study of prognostic models, to find out how acceptable they are. Interview data were entered into NVivo 10 and analysed using the five stages of Framework Analysis: (i) familiarisation, (ii) developing a thematic framework, (iii) indexing, (iv) charting, and (v) mapping and interpretation.

Findings The use of prognostic models was acceptable to patients and carers, and largely acceptable to clinicians. There was marked discrepancy however between the wishes of patients and carers for prognostic discussions, and the willingness of clinicians to initiate and conduct these conversations. Clinicians' reluctance was founded on the dual principles of working in patients' best interests and doing no harm, but was at odds with what patients and carers actually wanted.

Conclusion Prognostic models such as PiPS may be a useful adjunct to clinical decision making, but also a helpful tool for initiating difficult conversations at the end of life. In order to conduct these conversations skilfully, communication skills training tailored to end of life prognostic conversations is needed.

\section{Introduction}

There is increasing evidence that patients with incurable cancer approaching the end-of-life, their unpaid carers (including next-of-kin) and clinicians want to know how much time is left to live (Gwilliam et al., 2012; Kirk et al., 2004). Prognostic information can help with planning for the end of life and sorting out affairs in advance (Steinhauser et al., 2001). For carers, who may be anxious or exhausted, accurate prognostication can help with decisions about where care will take place. In a systematic review, Parker et al (2007) found that high levels of information are needed in palliative and end of life care, more so for caregivers, as the end approaches. For clinicians, prognostic information can help with making provision for continuing care, stopping treatments that are unlikely to be of benefit, and enabling as good a death as possible (Thomas, 2020).

It can be difficult to predict how long someone with cancer has left to live and clinicians' estimates tend to be inaccurate and over-optimistic (Glare et al., 2003). There are many variables to consider such as type of cancer, extent of metastatic spread, co-morbidities and performance status (Hui, 2015). To make predictions easier, and in an effort to improve accuracy, validated prognostic indicators have been developed, for example the Palliative Prognostic Index (PPI) (Morita et al., 1999) the Palliative Performance Scale (PPS) (Anderson et al., 1996), the Feliu Prognostic Nomogram (FPN) (Feliu et al., 
2001), the Palliative Prognostic (PaP) score (Glare and Virik, 2001), and our own Prognosis in Palliative care Study predictor models, PiPS-A and B (Gwilliam et al., 2011). These various prognostic models have similarities and differences, but principally use algorithms to estimate life expectancy through a combination of information about diagnosis, change in health status, symptom severity (such as dyspnoea, fatigue and cachexia), and blood test results to predict physiological deterioration.

The PiPS-A models and corresponding risk categories make predictions based on observable clinical variables; the PiPS-B models and risk categories additionally incorporate the results of blood tests. Our original, multi-centre study developed and validated the models in a prospective cohort of 1018 patients with advanced cancer, who were no longer undergoing disease-modifying treatment (Gwilliam et al., 2011). We used logistic regression to identify four variables with prognostic significance for two week survival, and eight variables with prognostic significance for two months survival. We found that the PiPS scores were able to predict whether a patient was likely to live for "days" (less than 14 days), "weeks" (between 2 and 7 weeks) or "months" (2 months or longer). Both PiPS-A and PiPS-B were found to be as accurate as, but no better than, an agreed multi-professional estimate of survival. To further validate the PiPS (and other) prognostic models, we conducted a large quantitative validation study with 1833 cancer patients at the end of life, the results of which have been published elsewhere (Kalpakidou et al 2018; Stone et al, 2021 a; Stone et al, 2021b). As part of the validation study we conducted a nested qualitative study to answer questions about acceptability of the models to patients, carers and clinicians. Unless an intervention is acceptable, it is unlikely to be implemented into clinical practice, as is known from low uptake of many promising interventions over the years (Muir Gray, 2001).

The results from the validation study showed that the prognostic models had acceptable discrimination and calibration, but none showed superiority to clinicians' predictions of survival. We concluded that before adopting these algorithms into clinical practice, they either need to demonstrate superior accuracy or other advantages over clinicians' predictions alone. Our qualitative data answer the second question about possible advantages of using models alongside clinical judgement. In this paper we present a fuller description of the methodology and findings of the qualitative data that are presented briefly in Stone et al (2021a and 2021b) and conclude that the models have potential utility in supporting clinicians to initiate difficult, but essential, conversations about prognoses that might otherwise be avoided.

\section{Methods}

A purposive sample of patients, carers and clinicians who had been asked to participate in the quantitative PiPS validation study in the Manchester and Derby areas (hospice, community and hospital) were asked to consider participation in a qualitative interview study. We took a framework approach to data analysis (Ritchie and Lewis 2003).

\section{Sample}


Twenty nine patients and 20 carers were recruited; all were relatives of the patients (see Tables 1 and 2 for patient and carer demographic details). The majority of patients $(25 / 29 ; 86 \%)$ were recruited from two hospices in the Greater Manchester area. Patients had received a cancer diagnosis and were eligible for enrolment into the PiPS validation study (incurable cancer with an estimated survival of less than 1 year). Five patients had declined to take part in the validation study; their reasons for refusal were explored during the interview. A smaller number of patients $(n=4)$ were recruited from hospital day care, and were receiving palliative care in a rural community NHS Trust. A total of 32 clinicians were recruited. The clinician sample was recruited pragmatically and comprised health care professionals who routinely cared for terminally ill patients and made prognostic predictions, such as palliative care specialists, oncologists, nurses and GPs (see Table 3 for clinicians' demographic details).

The patient and carer sample comprised patients with capacity and carers of patients with or without capacity, who had agreed to participate in the validation study. We also approached patients and carers who had declined to participate in the validation study. We purposively sampled patients and carers according to gender and age. These are known examples of factors that may influence the decision to receive prognostic information (Bury 1982, McNamara 2001, Chapple and Ziebland 2002, Sinding and Wiernikowski 2008, Walshe et al 2008).

\section{Table 1: Patient demographic details}




\begin{tabular}{|c|c|c|c|c|c|c|}
\hline$\underline{\underline{I D}}$ & Gender & $\underline{\text { Age }}$ & Primary tumour & Former Occupation & Setting & $\underline{\text { In validation study }}$ \\
\hline P1 & Male & 70 & Liver & Salesman & Hospice & Yes \\
\hline P2 & Female & 85 & Stomach & Carer & Hospice & Yes \\
\hline P3 & Male & 76 & Prostate & Joiner & Hospice & Yes \\
\hline P4 & Female & 61 & Breast & Chef & Hospice & Yes \\
\hline P5 & Male & 61 & Rectum & Manager & Hospice & Yes \\
\hline P6 & Female & 63 & Ovary & Teacher & Hospice & Yes \\
\hline P7 & Female & 71 & Skin & Teacher & Hospice & Yes \\
\hline P8 & Male & 63 & Pancreas & Accountant & Hospice & Yes \\
\hline P9 & Male & 80 & Lung & Printer & Hospice & Yes \\
\hline P10 & Male & 81 & Prostate & Manager & Hospice & Yes \\
\hline P11 & Male & 70 & Bile duct & Engineer & Hospice & Yes \\
\hline P12 & Male & 63 & Throat & Researcher & Hospice & Yes \\
\hline P13 & Female & 80 & Lymphoma & Tailor & Hospice & Yes \\
\hline P14 & Female & 67 & Pancreas & HSE inspector & Hospice & Yes \\
\hline P15 & Female & 61 & Bladder & Receptionist & Hospice & Yes \\
\hline P16 & Female & 84 & Colon & IT worker & Hospice & Yes \\
\hline P17 & Male & 64 & Myeloma & Police officer & Hospice & Yes \\
\hline P18 & Male & 65 & Oesophagus & Mill worker & Hospice & Yes \\
\hline P19 & Male & 79 & Lung & Boiler worker & Hospice & Yes \\
\hline P20 & Male & 88 & Prostate & Manager & Hospice & Yes \\
\hline$\overline{P 21}$ & Female & 92 & Lymphoma & Housewife & Hospice & No \\
\hline P22 & Male & 73 & Colon & Carer & Hospice & No \\
\hline P23 & Male & 58 & Oesophagus & Accountant & Hospice & No \\
\hline P24 & Female & 60 & Uterus & Housewife & Hospice & No \\
\hline P25 & Female & 69 & Breast & Housewife & Hospice & No \\
\hline P26 & Female & 85 & Neck & Researcher & Day care & Yes \\
\hline P27 & Female & 72 & Lung & Secretary & Day care & Yes \\
\hline P28 & Male & 62 & Bowel & Engineer & Day care & Yes \\
\hline P29 & Male & 69 & Prostate & Finance Advisor & Day care & Yes \\
\hline
\end{tabular}

Table 2: Carers' demographic details 


\begin{tabular}{|l|l|l|l|l|l|l|}
\hline$\underline{\text { ID }}$ & $\underline{\text { Gender }}$ & $\underline{\underline{\text { ge }}}$ & $\begin{array}{l}\text { Relationship to } \\
\text { patient }\end{array}$ & $\begin{array}{l}\text { Occupation/ Former } \\
\text { Occupation }\end{array}$ & $\underline{\text { Setting }}$ & $\begin{array}{l}\text { Patient in } \\
\text { validation study }\end{array}$ \\
\hline C1 & Female & 42 & Daughter & Unemployed & Hospice & Yes \\
\hline C2 & Female & 67 & Daughter & Company Director & Hospice & Yes \\
\hline C3 & Female & 32 & Daughter & Admin Clerk & Hospice & Yes \\
\hline C4 & Female & 48 & Daughter-in-law & Carer & Hospice & Yes \\
\hline C5 & Female & 63 & Daughter & Personal assistant & Hospice & Yes \\
\hline C6 & Female & 78 & Wife & Teacher & Hospice & Yes \\
\hline C7 & Female & 35 & Wife & Housewife & Hospice & Yes \\
\hline C8 & Female & 86 & Wife & Shop Owner & Hospice & Yes \\
\hline C9 & Male & 59 & Son & Entrepreneur & Hospice & Yes \\
\hline C10 & Female & 46 & Daughter & Carer & Hospice & Yes \\
\hline C11 & Female & 60 & Daughter & Nurse & Hospice & Yes \\
\hline C12 & Female & 65 & Daughter & NHS Admin Clerk & Hospice & Yes \\
\hline C13 & Female & 53 & Daughter & Secretary & Hospice & Yes \\
\hline C14 & Female & 75 & Wife & Seamstress & Hospice & No \\
\hline C15 & Male & 50 & Son & Builder & Hospice & No \\
\hline C16 & Male & 65 & Brother & Engineer & Hospice & No \\
\hline C17 & Male & 64 & Son & Engineer & Hospice & No \\
\hline C18 & Female & 56 & Wife & Secretary & $\begin{array}{l}\text { Day } \\
\text { care }\end{array}$ & Yes \\
\hline C19 & Male & 63 & Husband & Roofer & $\begin{array}{l}\text { Day } \\
\text { care }\end{array}$ & Yes \\
\hline C20 & Female & 62 & Wife & Book keeper & $\begin{array}{l}\text { Day } \\
\text { care }\end{array}$ & Yes \\
\hline
\end{tabular}

Table 3: Health care professionals' demographic details 


\begin{tabular}{|l|l|l|l|}
\hline$\underline{\text { ID number }}$ & $\underline{\text { Gender }}$ & $\underline{\text { Age }}$ & $\underline{\text { Professional group } / \text { grade }}$ \\
\hline H1 & F & 28 & Staff nurse (band 5) \\
\hline H2 & F & 23 & Staff nurse (band 5) \\
\hline H3 & F & 25 & Staff nurse (band 5) \\
\hline H4 & M & 38 & GP \\
\hline H5 & M & 29 & Trainee doctor (F2: Foundation Year 2) \\
\hline H6 & F & 34 & Trainee doctor (F1: Foundation Year 1) \\
\hline H7 & M & 42 & Consultant (palliative care) \\
\hline H8 & F & 50 & Associate Specialist (palliative care) \\
\hline H9 & M & 39 & GP \\
\hline H10 & M & 32 & GP \\
\hline H11 & F & 47 & GP \\
\hline H12 & F & 50 & GP \\
\hline H13 & M & 45 & Consultant (palliative care) \\
\hline H14 & M & 57 & Consultant (palliative care) \\
\hline H15 & M & 28 & Trainee doctor (F2) \\
\hline H16 & F & 30 & Specialist Trainee doctor (palliative care) \\
\hline H17 & F & 30 & Specialist trainee doctor (palliative care) \\
\hline H18 & F & 30 & GP \\
\hline H19 & F & 34 & GP \\
\hline H20 & M & 48 & Consultant oncologist \\
\hline H21 & F & 36 & Specialist palliative care nurse (band 7) \\
\hline H22 & F & 45 & Specialist palliative care nurse (band 7) \\
\hline H23 & F & 42 & Consultant (palliative care) \\
\hline H24 & F & 44 & Consultant (palliative care) \\
\hline H25 & F & 31 & Trainee doctor (F2) \\
\hline H26 & F & 54 & Associate specialist (palliative care) \\
\hline H27 & F & 45 & Consultant (palliative care) \\
\hline H28 & F & 46 & Consultant oncologist \\
\hline H29 & F & 39 & Consultant (palliative care) \\
\hline H30 & F & 45 & Consultant (palliative care) \\
\hline H31 & M & 44 & Consultant (palliative care) \\
\hline H32 & F & 50 & Specialist community practitioner (district nurse, $)$ \\
\hline
\end{tabular}

\section{Interviews}

Interviews were face-to-face, semi-structured and interactive, and explored the acceptability of PiPS and other prognostic models. We used topic guides that were iterative to allow new themes that emerged during interviews to be explored with future participants. Patient/carer interview topic guides included: experiences of being approached to take part in the PiPS2 prognostic study; perspectives on the development and use of prognostic indicators; views and opinions about the best and most sensitive 
ways to present prognostic information to patients and or relatives/carers; opinions about the usefulness of prognostic models.

Clinicians were shown the prognostic models, and commented on their perceived clinical utility (e.g. ease of completion and interpretability of outputs). Clinician topic guides included: experiences of making predictions of survival and telling patients/carers; information currently shared with patients/carers about prognosis and how it is conveyed; opinions on the development and use in clinical practice of prognostic indicators/tools; barriers and facilitators to clinical use.

\section{Data analysis}

Interview data were entered into NVivo 10 and analysed using the five stages of Framework Analysis (Ritchie and Lewis, 2003): (i) familiarisation, (ii) developing a thematic framework, (iii) indexing, (iv) charting, and (v) mapping and interpretation. During the first stage (familiarisation), the research team became immersed in the data (Srivastava and Thomson, 2009) by reading and re-reading the transcripts and discussing emerging themes. Then, a thematic framework was developed based on the topic guide (Bernard and Ryan, 2010). After this, transcripts were indexed (coded) line by line using the thematic framework, but remaining open to new themes that emerged (Ritchie and Spencer, 1994). Next, the data were entered into a chart so that coded extracts could be attributed to individual participants. Finally, participants' views were compared and contrasted, and the data were presented schematically (mapping). Rival explanations were explored.

An iterative and inductive approach to analysis was followed so that data analysis started alongside data collection. Themes and issues identified from interviews then informed further questions in ongoing and future interviews. Memoranda and notes were written about emerging themes, to summarise or analyse a point, and relate emerging ideas and concepts to existing literature. The qualitative research team met on a regular basis to discuss the development of emerging codes, themes, categories and interpretations.

\section{Findings}

\section{Patients' and carers' views on prognostication}

The majority of patients with advanced cancer and their carers expressed a desire for detailed information from clinicians about patients' life expectancy, for example:

Very few patients and carers reported that they received this information, or that if they did receive it, it was not expressed clearly. A number who had asked about their life expectancy commented that doctors tended to be vague, over optimistic and unwilling to deliver news that was considered bad or uncertain:

"Doctors are reluctant to give estimates of survival, their approach is very uncommunicative. When the prognosis is negative, you have to really probe and ask lots of questions, doctors would rather get out of giving you negative information altogether. I think it's because they don't want to give people bad news". (male patient, aged 61; hospice; ID P5) 
The main reason both patients and carers gave for wanting more detailed prognostic information was to make plans and sort out family affairs. This related to both individual and family finances, and making funeral arrangements:

"I think if I had a rough idea I think that would make things a little bit easier for me, with regards to organising his affairs and planning his funeral." (female carer; aged 35; hospice; ID C7).

Clearly, accurate prognostic information would give patients and carers a clearer time frame within which to plan for the immediate and longer term future.

\section{Patients' and carers' views on PiPS}

All of the patients and carers considered that the PiPS prognostic models were acceptable for use in clinical practice and could potentially be a useful aid to predicting life expectancy with greater accuracy. As one patient commented:

"I think the tool is useful as it gives an indication of time left for people, however accurate it might be, that doctors can then pass on. At least it's not this big open space that I have at the moment, the tool would help narrow the time frame, at least to give patients like me some idea". (female patient; aged 71; hospice; ID P7)

Additionally, as clinicians were reported to be either vague about life expectancy or reluctant to discuss it, patients and carers speculated that PiPS could help clinicians initiate sensitive conversations about prognoses. Currently, it appeared that patients were often the first to broach the subject:

At the end of the day doctors leave patients to ask about prognostic information because they [Drs] don't want to volunteer the uncertainty. Any tool that helps must be useful for all concerned, especially in helping doctors explain this sort of information to patients". (male patient; aged 73; hospice; ID P22)

A minority of patients stated, however, that they did not wish to receive detailed prognostic information but were happy for relatives or carers to receive it. For example:

"My wife doesn't want to know what time she has left, she doesn't but we decided that I should be given detailed prognostic information". (male carer; aged 63; community; ID C19)

Overall therefore patients and carers were consistently positive about prognostic models, albeit in a few cases, divided on who should receive the information.

\section{Clinicians' views on prognostication}

Corroborating the accounts of patients and carers, the clinicians commented on both the complex nature of estimating length of survival for patients, and the 'vague' language they would use to discuss estimations to couch the uncertainty of an accurate prediction. 
"If there's nothing in the patient's disease trajectory which would suggest a change in their condition, then I think it's very difficult to prognosticate, so I think you'd struggle to give an accurate prognosis if somebody's condition doesn't change. If somebody's condition deteriorates, then it's the rapidity of that decline that gives you the best guide. And then it is just a guide". (male oncologist; aged 48; ID H20)

"Generally I try and keep the answer vague, I mean, you're obviously able to give an indication as to when someone's obviously breathing their last or when someone is very unwell, but when someone is in that stage where they're kind of on a knife edge, I always say, well, it could be the next few weeks, but at the same time we've all been surprised and seen people last for months and months. So it's about discussing the uncertainness involved in predicting survival". (female palliative care consultant; aged 45; ID H30)

The other reason that clinicians reported for being vague, was to be kind and sensitive to the needs of patients, as a junior doctor explained:

"Patients do ask but I keep it quite vague, especially just trying to sort of judge how much a patient wants to sort of talk to you about it. Yes, I wouldn't just, answer and say weeks, or whatever, I think you just have to be quite kind and gentle. Also some patients just don't want to know about prognosis". (female; second year trainee doctor; aged 31; ID H25)

If the patient and carer are giving cues that they do not want prognostic detail, this is evidently the most appropriate response, but as reported earlier, most patients and carers did want to know.

\section{Clinicians' views on PiPS}

Reflecting on the challenges reported with accurate prognostication, the majority of clinicians considered PiPS to be a user-friendly algorithm that could offer a more accurate adjunct to estimating patients' prognoses, than clinical judgement alone. For example a specialist palliative care nurse stated:

"When communicating prognostic information it would be nice to wrap it around something ... you know, we've filled in a tool, what we do is we look at you, we look at lots of things, such as your symptoms, we take them into consideration, and what the tool shows us that you're very poorly and then I would maybe wait for the, how long question". (female; specialist palliative care nurse; aged 45; ID H22).

A possible outcome of the validation study, however, was that the predictive power of PiPS might be similar to clinicians' estimates. Clinicians were asked whether they would still find PiPS useful if this was the case. They affirmed that they would, because it could improve confidence in making predictions, particularly for less experienced staff:

"Even if PiPS is no more accurate than a clinician's estimate it would be useful ... especially with less experienced staff, as when you're a junior doctor you don't necessarily have the experience to be confident in identifying a dying patient, so often you're very hopeful ... you could err on the side of false reassurance. So I think because of the lack of experience, I think it's more difficult for junior staff to prognosticate accurately" (male palliative care consultant; aged 45; ID H30) 
In addition, clinicians agreed with patients and carers that PiPS could help to both initiate and conduct difficult conversations about prognoses, that they might otherwise side-step. Some also said that it could help support decisions about the most appropriate - and compassionate - management of patients' symptoms, given the time left. This was particularly the case for junior doctors who reported that they sometimes had difficulty being 'heard' in MDTs:

"I think PiPS is a useful tool especially for us junior palliative care staff working in a hospital settings trying to convince more senior clinicians about a patient's prognosis. It also aids the decision about stopping curative treatment or not and thinking what is best for the patient and the time they have left". (male F2 trainee doctor; aged 29; ID H5)

Finally, clinicians considered that PiPS could provide useful leverage for discharge home with a continuing healthcare package (fully funded care from the NHS):

"This sort of tool gives weight to a commissioner, say if somebody wants to die at home, we think they meet the Continuing Healthcare criteria, it would be helpful for commissioners to know what length of time they're going to be funding that care. So having PiPS in use in clinical practice could help strengthen discharge planning". (male palliative care consultant; aged 42; ID H7)

Clinicians were mostly very positive about PiPS therefore and the potential utility of the model in routine practice.

\section{Barriers to use of PiPS}

Some clinicians expressed reservations about PiPS. A minority stated that they preferred to rely on their own clinical judgement, and would not use a model to support their predictions. These clinicians were either confident in their ability to make reasonably accurate predictions, or perhaps avoided prognostic conversations. A further minority felt that using PiPS-B might be inappropriate since this model required the use of blood tests. This related both to the practicalities of organising blood tests for patients with advanced cancer, and the ethical implications of drawing blood from very unwell patients.

An important barrier was the recurring theme of avoiding prognostic discussions with patients and carers. The use of 'vague' language, referred to earlier, was described by some clinicians as the challenge of balancing a kinder more optimistic stance, with being realistic with patients considered not ready for receiving devastating news, as this palliative care consultant commented:

"If they're [patients] coping quite well with their perception of actual time left and we as clinicians change that quite drastically, that's when you can do harm, and it can seem that people deteriorate very quickly then. So there's that difficult line to tread between giving patients more optimistic information which may give patients time to still function, so they can plan things that are important, or taking away hope and doing harm". (female palliative care consultant; aged 44; ID H24) 
There is a balance therefore between giving patients realistic hope, and ensuring they know that time is limited. Other patients and carers were reported to use a high level of denial as a coping mechanism, and clinicians were reluctant to erode this. A palliative care consultant commented:

"It's not that always that clinicians are over estimating prognosis it may be that sometimes, we can see that a patient is operating at a high level of denial, we wouldn't necessarily challenge if we thought that was a useful coping mechanism for them, any challenge may cause stress and harm to the patient, but it might be that we then have to subtly bring along the patient and family's understanding over time to try and prepare them for what's going to happen". (male palliative care consultant; aged 57; ID H14)

These justifications for evasive conversations appear at face value to be entirely reasonable, but in many cases might be at odds with what patients and carers actually want.

\section{Discussion}

This qualitative interview study, nested in a large scale validation of PiPS and other prognostic models, found that both clinical prognostication and the use of prognostic model/risk categories were acceptable to patients and carers, and largely acceptable to clinicians. There was however a mismatch between patients' and carers' desire to discuss prognoses, and clinicians' willingness to talk. Prognostic models may offer a 'way in' to difficult conversations that might otherwise be avoided.

Patients and carers wanted accurate prognostic information. They were not always able to access it due to reported reticence of clinicians who couched predictions of life expectancy in vague terms, or avoided conversations altogether. They considered that use of prognostic models by clinicians could be a 'way in' to difficult prognostic discussions.

Clinicians were also largely supportive of modelling as a useful adjunct to clinical decision making, particularly for less experienced staff. They reported that predictions were often difficult, because there are so many variables to consider, and admitted using vague language in prognostic discussions with patients and carers. Most could see the value of additional data to support their decisions about treatment, however, and recommendations for discharge home to continuing health care when patients were at the end of life. A few could also envisage using a model to initiate difficult, prognostic discussions with patients and carers. Senior clinicians considered that their junior colleagues would benefit most.

Some clinicians were less positive about prognostic models however. There were practical and ethical reasons for this such as drawing blood from very unwell patients. The other major consideration was reluctance to erode hope or denial as coping mechanisms.

Patients appear to be poor at predicting their own survival (Gwilliam et al., 2012), but most want to know how long they have left (Back and Arnold, 2006). It is perhaps no surprise therefore that patients and carers welcomed a model that could potentially predict life expectancy with a degree of accuracy. The 
paradox however is that although patients and carers wanted to know, clinicians appeared reluctant to give this information. Clinicians reported that they preferred to be vague in their estimations of survival to avoid the negative impact of knowing the truth which could erode hope, or denial, as coping strategies.

While the reasons for being vague about prognosis come from a position of caring about patients and doing the best for them, desire to 'protect' them in this way might not be in accordance with their wishes. Although there is plenty of evidence for the importance of realistic hope in palliative care (Hancock at al., 2007), and some evidence of denial as a potent coping mechanism for some (Zimmermann, 2004), for the majority of patients and carers honesty is preferred. It gives patients and families sufficient time to prepare for the death, and to make plans for their loved ones (Steinhauser et al., 2001); it also chimes with contemporary values of autonomy and shared decision making in healthcare.

Perhaps reluctance to have prognostic discussions is due to discomfort with broaching the subject and lack of confidence in having conversations, rather than doing what is best for the patient (Wolfe and Cleary, 2007; Mack and Smith, 2012). In a systematic review of 46 studies on truth telling in palliative care, Hancock et al., (2007) found that although most clinicians agreed that they should tell patients and carers the truth about prognoses, there was a tendency to avoid such sensitive conversations. There is other evidence that clinicians find it difficult to break bad news about transition to the dying phase (Barclay et al 2011). As suggested by patients, carers and some clinicians in our study, using a prognostic model could be a 'way in' to these difficult discussions.

We know from the communications skills literature, that doctors and nurses shy away from conversations they perceive to be difficult because they imagine 'opening a can of worms' of emotion and existential crises that will be unmanageable (Maguire et al., 1996; Heaven and Maguire, 1997; Griffiths et al., 2010). In the UK and elsewhere curative models of care pervade. The reality, when bad news is broken, is often far more mundane however, with patients often wishing to discuss practical rather than existential concerns (Connolly et al 2010, Griffiths et al 2010). Clinicians' fears may therefore be largely unfounded.

It would appear that there is a need for training clinicians in the specific communication skills that are required when discussing poor prognoses with patients and carers at the end of life (Friedrichsen et al., 2000; Clayton et al., 2005; Cartwright et al., 2014). Despite the comments of some clinicians in this study it would seem likely that such training should be offered to all clinicians working in palliative and end of life care, and not just their junior colleagues. A number of authors have written about the skills required. For example Wenrich et al (2001) describe the tenets as honesty, sensitivity and readiness to talk when patients are themselves ready. Campbell et al. (2010) discuss treading a fine line between hope and realism. Clayton et al. (2007) developed guidelines for communicating prognoses based on a systematic review of the literature. They proposed an acronym, PREPARED, to help clinicians to remember the key components of prognostic communications: Prepare for the discussion; Relate to the person; Elicit patient and carer preferences; Provide information; Acknowledge emotions and concerns; (foster) Realistic hope; Encourage questions; and Document. There is a need for further research on the implementation of 
frameworks such as this for prognostic discussions. As Hagerty et al., (2005) concluded in a systematic review of research on communicating prognoses, most research is at the early rather than later stages of the disease.

This nested qualitative study is not without limitations. Relatively few views $(n=5)$ were represented from patients who did not want to participate in the quantitative validation study. The reason they gave for refusing recruitment to the validation study was that they did not want to give blood. These patients were however equally positive about PiPS as those patients who participated in the main study. Another small number $(n=4)$ of patients declined to take part in both the validation study and nested qualitative study. Reasons given were that they were in too much pain or discomfort to take part in either study.

The number of community patients interviewed was small $(n=4)$, so findings from these patients should be interpreted with caution. It appears that their views were slightly different from the other participants because they were generally at an earlier stage in the disease trajectory, and not as ready to think about how long they had left to live.

\section{Conclusion}

There is marked discrepancy between the wishes of patients and carers for prognostic discussions, and the willingness of clinicians to initiate and conduct these conversations towards the end of life.

Clinicians' reluctance is founded on the dual principles of working in patients' best interests and doing no harm, but is at odds with what patients and carers actually want and need at the end of life, and the prevailing ethos in palliative care of openness and honesty. This challenge is nothing new (Todd and Still 1993). Prognostic models such as PiPS may be a useful adjunct to clinical decision making, but as importantly, a helpful tool for initiating difficult conversations about transition to the dying phase. In order to conduct these conversations skilfully, communication skills training tailored to end of life prognostic conversations is needed.

\section{Declarations}

Ethics approval and consent to participate:

The study received ethical approval from the Yorkshire and Humber - Leeds East Research Ethics Committee (reference number: 16/YH/0132). All participants were given more than 24 hours to consider participation and signed a consent form prior to their interview.

Consent for publication: Not applicable

Availability of data and materials: The datasets used and/or analysed during the current study are available from the corresponding author on reasonable request.

Competing interests: The authors declare that they have no competing interests. 
Funding: This paper presents independent research funded by the National Institute for Health Research, Health Technology Assessment (HTA) programme (NIHR-HTA 13/20/01). Awarded to PS, CT, JG, VK.

Authors' contributions: JG Conceptualization, Writing - original draft; KS Investigation, Writing - review \& editing; PS Conceptualization, Writing - review \& editing; AK Project administration; VK Writing - review \& editing; PB Writing - review \& editing; DF Writing - review \& editing; CT Writing - review \& editing.

Acknowledgements: Not applicable

\section{References}

Anderson, F., Downing, G.M., Hill, J., Casorso, L. and Lerch, N. 1996. Palliative performance scale (PPS): a new tool. J Palliat Care.12(1): p. 5-11.

Back, A. L. \& Arnold, R. M. 2006. Discussing Prognosis: "How Much Do You Want to Know?" Talking to Patients Who Are Prepared for Explicit Information. Journal of Clinical Oncology, 24(25), pp. 4209-4212.

Bernard, R. H. \& Ryan, G. W., 2010. Analyzing Qualitative Data: Systematic Approaches. New York: SAGE Publications.

Barclay, S, Momen, N, Case-Upton, S. End of life conversations with heart failure patients: a systematic review and narrative analysis. Br J Gen Pract 2011; 61: e49-e61.

Bury M, Chronic illness as biographical disruption. Sociology of Health \& Illness, 1982. 4(2): p. 167-82.

Campbell, T.C., Carey, E.C., Jackson, V.A., Saraiya, B., Yang, H.B., Bacl, A.L. \& Arnold, R.M., 2010.

Discussing Prognosis: Balancing Hope and Realism. The Cancer Journal, 16(5), pp. 461-466.

Cartwright, L. A., Dumenci, L., Siminoff, L. A. \& Matsuyama, R. K., 2014. Cancer Patients' Understanding of Prognostic Information. Journal of Cancer Education, 29(2), pp. 311-317.

Chapple, A. and Ziebland, S. 2002. Prostate cancer: embodied experience and perceptions of masculinity. Sociology of Health \& IIIness. 24(6): p. 820 - 841.

Connolly, M., Perryman, P., McKenna, Y., Orford, J., Thomson, L., Shuttleworth, J. and Cocksedge, S. 2010. SAGE \& THYME ${ }^{\mathrm{TM}}$ : A model for training health and social care professionals in patient-focussed support Patient Education and Counseling 791 p. 87-93,

Clayton, J. M., Butow, P.N. \& Tattersall, M. H. N., 2005. When and How to Initaite Discussion About Prognosis and End-of-Life Issues with Terminally III Patients. Journal of Pain and Symptom Management, 30(2), pp. 132-144.

Clayton, J.M., Hancock, K.M., Butow, P.N., Tattersall., M.H. \& Currow, D.C., 2007. Clinical practice guidelines for communicating prognosis and end of life issues with adults in the advanced stages of life limiting 
illness, and their caregivers. Medical Journal of Australia Supplement, Volume, 186(12), pp. S77-S105

Feliu, J., Jimenez-Gordo, A.M., Madero, R., Rodriguez-Aizcorbe, J.R., Espinosa, E., Castro, J., et al. 2011. Development and validation of a prognostic nomogram for terminally ill cancer patients. $\mathrm{J}$ Natl Cancer Inst. 103(21): p. 1613-20.

Friedrichsen, M. J., Strang, P. M. \& Carlsson, M. E. 2000. Breaking bad news in the transition from curative to palliative cancer care - patient's view of the doctor giving the information. Support Care Cancer, Volume 8, pp. 472-478.

Glare, P., Virik, K., Jones, M., Hudson, M., Eychmuller, S., Simes, J. \& Christakis, N. 2003. A systematic review of physicians' survival predictors in terminally ill cancer patients. BMJ, Volume 327, p. 195.

Glare, P. and Virik, K. 2001. Independent prospective validation of the PaP score in terminally ill patients referred to a hospital-based palliative medicine consultation service. J Pain Symptom Manage. 22(5): $\mathrm{p}$. 891-8.

Griffiths, J., Ewing, G. \& Rogers, M. 2010. "Moving swiftly on." Psychological support provided by district nurses to patients with palliative care needs. Cancer nursing, 33(5), pp. 390-397.

Gwilliam, B., Todd, C. Gittins, M. Roberts, C. Kelly, L., Barclay, S. and Stone, P.C. 2011. Development of Prognosis in Palliative care Study (PiPS) predictor models to improve prognostication in advanced cancer: propspective cohort study. BMJ, Volume 343.

Gwilliam, B., Keeley, C., Todd, C., Roberts, C., Gittins, M., Barclay, S. and Stone, P. 2012. Prognosticating in patients with advanced cancer - observational study comparing the accuracy of clinicians' and patients' estimates of survival. Annals of Oncology, Volume 24, pp. 482-488.

Hagerty, R. G., Butow, P.N., Ellis, P.M., Dimitry, S. \& Tattersall, M.H.N., 2005. Communicating prognosis in cancer care: a systematic review of the literature. Annals of Oncology, Volume 16, pp. 1005-1053.

Hancock, K., Clayton, J.M., Parker, S.M., Wall der, S., Carrick, S., Currow, D., Ghersi, D., Glare, P., Hagerty, R. and Tattersall, M.H. 2007. Truth-telling in discussing prognosis in advanced life-limiting illnesses: a systematic review. Palliative Medicine. 21. pp. 507-517.

Hui, D., 2015. Prognostication of Survival in Patients with Advanced Cacner: Predicting the Unpredictable?. Cancer Control, 22(4), pp. 489-497.

Kalpakidou, A.K., Todd, C., Keeley, V., Griffiths, J., Spencer, K., Vickerstaff, V., Omar, R.Z. and Stone, P. The Prognosis in Palliative care Study II (PiPS2): study protocol for a multi-centre, prospective, observational, cohort study. BMC Palliative Care 2018 17:101 doi:10.1186/s12904-018-0352-y

Kirk, P., Kirk, I. \& Kristjanson, L. J., 2004. What do patients receiving palliative care for cancer and their families want to be told? A Canadian and Australian qualitative study. BMJ, Volume 328, pp. 1-7. 
Mack, J. W. and Smith, T. J. 2012. Reasons Why Physicians Do Not Have Discussions About Poor Prognosis, Why It Matters, and What Can Be Improved. Journal of Clinical Oncology, 30(22), pp. 27152717.

McNamara, B. 2001. Fragile lives: Death, dying and care. Sydney: Allen \& Unwin.

Maguire, P., Faulkner, A., Booth, K., Elliott, C. \& Hillier, V. 1996. Helping cancer patients disclose their concerns. European Journal of Cancer, 32(1), pp. 78-81.

Maguire, P. \& Heaven, C. M., 1997. Disclosure of concerns by hospice patients and their identification by nurses. Palliative Medicine, 11(4), pp. 283-290.

Morita, T., Tsunoda, J., Inoue, S. and Chihara, S. 1999. The Palliative Prognostic Index: a scoring system for survival prediction of terminally ill cancer patients. Support Care Cancer.7(3) p. 128-33.

Muir Gray, J. A., 2001. Evidence-based Healthcare. 2 ed. London: Churchill Livingston.

Parker, S. M., Clayton, J.M., Hancock, K., Walder, S., Butow, P.N., Carrick, S., Currow, D., Ghersi, D., Glare, P., Hagerty, H. \& Tattersall, M.H.N, 2007. A Systematic Review of Prognostic/End-of-Life Communication with Adults in the Advanced Stages of Life-Limiting Illness: Patient/Caregiver Preferences for the Content, Style, and Timing of Information. Journal of Pain and Symptom Management, Volume 34, pp. 81-93.

Ritchie, J. \& Lewis, J., 2003. Qualitative Research Practice: A Guide for Social Science Students and Researchers. 1 ed. New York: SAGE Publications Ltd.

Ritchie, J. \& Spencer, L., 1994. Qualitative data analysis for applied policy, in Analysing qualitative data, Bryman A and Burgess R, Editors. Routledge: Oxon. 173 - 194.

Sinding, C. and Wiernikowski, J. 2008. Disruption foreclosed: older women's cancer narratives. Health: an Interdisciplinary Journal for the Social Study of Health, Illness \& Medicine. 12(3): p. 389-411.

Srivastava, A. \& Thomson, S. B. 2009. Framework Analysis: A Qualitative Methodology for Applied Policy Research. Journal of Administration and Governance, 4(2), pp. 72-79.

Steinhauser, K. E., Christakis, N.A., Clipp, E.C., McNeilly, M., Grambow, S., Parker, J. \& Tulsky, J.A., 2001. Preparing for the end of life: preferences of patients, families, physicians, and other care providers. Journal of pain and symptom management, 22(3), pp. 727-37.

Stone P, Kalpakidou A, Todd C, Griffiths J, Keeley V, Spencer K, Buckle P, Finlay D, Vickerstaff V \& Omar RZ 2021a.Prognostic models of survival in patients with advanced incurable cancer: the PiPS2 observational study. Health Technology Assessment, 25(28) https://doi.org/10.3310/hta25280

Stone P, Kalpakidou A, Todd C, Griffiths J, Keeley V, Spencer K, Buckle P, Finlay D, Vickerstaff V \& Omar RZ 2021b.The Prognosis in Palliative care Study II (PiPS2): A prospective observational validation study 
of a prognostic tool with an embedded qualitative evaluation. Published: April 28, 2021. https://doi.org/10.1371/journal.pone.0249297

Thomas (2020) Gold Standards Framework https://www.goldstandardsframework.org.uk/cdcontent/uploads/files/PIG/NEW\%20PIG\%20-\%20\%20\%2020.1.17\%20KT\%20vs17.pdf [accessed 08/04/2020]

Todd, C. and Still, A. 1993. General practitioners' strategies and tactics of communication with the terminally ill. Family Practice. 10(3) 268-276

Wenrich, M. D., Curtis, R., Shannon, S.E., Carline, J.D., Ambrozy, D.M. \& Ramsey, P.G. 2001. Communicating With Dying Patients Within the Spectrum of Medical Care From Terminal Diagnosis to Death. Archives of Internal Medicine, Volume 161, pp. 868-874.

Wolfe, J. \& Cleary, P. D. 2007. Hope and Prognostic Disclosure. Journal of Clincal Oncology, 25(35), pp. 5636-5642.

Walshe, C., Todd, C., Caress, A-L., and Chew-Graham, C. 2008. Judgements about fellow professionals and the management of patients receiving palliative care in primary care: a qualitative sub-study. $\mathrm{Br} \mathrm{J}$ Gen Prac. 58(549): p. 264-72.

Zimmermann, C., 2004. Denial of impending death: a discourse analysis of the palliative care literature. Social Science and Medicine, 59(8), pp. 1769-1780. 